\title{
O olhar do professor da sala comum e os aspectos emocionais dos estudantes
}

\section{The look of the common room teacher and the emotional aspects of the students}

\author{
Vivian Almada Dutra Salmito ${ }^{1 *}$, Dina Mara Formiga da Silva ${ }^{1}$, Raianny de sousa ${ }^{1}$, Cristiane \\ Sales Leitão ${ }^{2}$, Cybelle Façanha Medeiros Linard ${ }^{1}$, Lídia Andrade Lourinho ${ }^{3}$
}

\section{RESUMO}

Introdução: Algumas situações despertam a atenção dos profissionais da educação e da saúde, acerca das causas do crescente número de encaminhamentos de crianças e adolescentes aos especialistas, que apresentam queixas escolares relacionadas a problemas de aprendizagem, problemas comportamentais e emocionais. Objetivo: compreender o olhar do professor da sala comum, os aspectos emocionais dos estudantes e suas possibilidades. Materiais e métodos: O presente estudo é um recorte de uma pesquisa maior. Em que para conduzir a pesquisa, utilizou-se o método de pesquisa descritiva e exploratória com abordagem quantitativa. Resultados e Discussão: Em relação aos aspectos relacionados a fatores emocionais na visão dos professores, os dados evidenciam que muitos destes, atribuem aos estudantes problemas emocionais, que acarretam dificuldades e limitações no processo de aprendizagem. Conclusões: Conclui-se que na percepção dos professores participantes da pesquisa, a maioria dos estudantes apresenta comportamentos que discrepam dos parâmetros preestabelecidos pela instituição escolar.

Palavras-chave: Emocional; Estudantes; Professor; Sala de aula;

\begin{abstract}
Introduction: Some situations attract the attention of education and health professionals, regarding the causes of the growing number of referrals of children and adolescents to specialists, who present school complaints related to learning problems, behavioral and emotional problems. Objective: to understand the look of the common room teacher, the emotional aspects of students and their possibilities. Materials and methods: The present study is a clipping of a larger research. In which to conduct the research, the descriptive and exploratory research method with quantitative approach was used. Results and Discussion: Regarding aspects related to emotional factors in the teachers' vision, the data show that many of these attribute emotional problems to students, which cause difficulties and limitations in the learning process. Conclusions: It is concluded that in the perception of the teachers participating in the research, most students present behaviors that dismay the parameters preestablished by the school institution.
\end{abstract}

\footnotetext{
${ }^{1}$ Universidade Estadual do Ceará. *E-mail: viviansalmito18@gmailcom

${ }^{2}$ Assenbléia Legislativa do Ceará

${ }^{3}$ Faculdade Luciano Feijão.
} 


\section{INTRODUÇÃO}

Os artigos devem conter no máximo 10 mil palavras em folha tamanho A4. As margens laterais devem estar em $3 \mathrm{~cm}$ e as margens superior e inferior, $2,5 \mathrm{~cm}$.

O texto do artigo deve ser digitado em fonte Times New Roman, corpo 12, justificado, em espaço 1,5, e empregar itálico para termos estrangeiros, em vez de sublinhado.

Nos dias atuais, deparamo-nos com muitas situações que despertam a atenção dos profissionais da educação e da saúde, acerca das causas do crescente número de encaminhamentos de crianças e adolescentes aos especialistas, que apresentam queixas escolares relacionadas a problemas de aprendizagem, problemas comportamentais e emocionais.

De acordo com alguns autores, como Moysés (1990), Patto (1990) e Souza (2009), faz-se necessário aprofundar essa temática, por reconhecer que a criança que está matriculada na escola, está inserida em um contexto de interações e relações, as quais precisam ser avaliadas e questionadas, para não justificar ou transferir para o educando ou para sua família a total responsabilidade de sua dificuldade ou limitação apresentada na escola, ocasionando o fracasso escolar, tendo por consequência a repetência, o abandono e a evasão.

Rossato (2009) apontou que demandar ao estudante total responsabilidade pela sua dificuldade, pode eximir outros atores envolvidos no contexto, como também limitar e prejudicar uma análise dos demais fatores que influenciam o contexto escolar.

Para compreender melhor esse fenômeno, é necessário considerar os diversos atores envolvidos em sua produção, mas que não foram incluídos na análise do processo sendo desconsiderados, concentrando o foco somente no estudante (Souza, 2007).

A partir deste contexto, objetivou-se compreender o olhar do professor da sala comum, os aspectos emocionais dos estudantes e suas possibilidades.

\section{METODOLOGIA E MÉTODOS}


O presente estudo é um recorte de uma pesquisa maior. Em que para conduzir a pesquisa, utilizou-se o método de pesquisa descritiva e exploratória com abordagem quantitativa.

Segundo Rudio (2002), a pesquisa descritiva apresenta as particularidades de um determinado grupo e sua forma de interpretar. Para Gil (2008), as pesquisas descritivas têm como foco o detalhamento dos aspectos de um fenômeno e o estabelecimento de relações entre variáveis.

As pesquisas com abordagem quantitativas são utilizadas para responder a perguntas que buscam investigar características de um grupo ou população diante de alguma temática, também sendo uma forma de estar sensibilizado aos problemas de ordem social. Desta forma, é possível relacionar a pesquisa ao contexto em que se insere socialmente para enriquecer o trabalho (GATTI, 2012; PEREIRA; ORTIGÃO, 2016). Os dados, de alguma forma, conseguem expressar a realidade, ainda que se utilize indicativos e frequências (GATTI, 2012; PEREIRA; ORTIGÃO, 2016).

Desta forma, a pesquisa foi realizada em 40 escolas públicas inseridas no Distrito de Educação VI do município de Fortaleza - CE, que abrange 29 bairros: Aerolândia, Alto da Balança, Ancuri, Barroso, Boa Vista, Cajazeiras, Cambeba, Cidade dos Funcionários, Coaçu, Curió, Conjunto Palmeiras, Dias Macedo, Edson Queiroz, Guajeru, Jangurussu, José Alencar, Jardim das Oliveiras, Lagoa Redonda, Messejana, Parque Dois Irmãos, Parque Iracema, Parque Manibura, Paupina, Passaré, Sabiaguaba, São Bento, Santa Maria, Sapiranga e Coité. A Secretaria Municipal da Educação (SME) possui seis Distritos de Educação, os quais são distribuídos por toda a Fortaleza e são responsáveis pelo acompanhamento das escolas da Rede de Ensino pertencentes a sua região. Cada Distrito de Educação é organizado mantendo a mesma estrutura organizacional da SME, tendo uma gerência para a Educação Infantil, uma para o Ensino Fundamental e uma para a Gestão.

Os participantes da pesquisa foram 465 professores do $1^{\circ}$ ao $5^{\circ}$ ano que, durante o período de coleta de dados, exerciam suas funções profissionais de modo regular nas escolas que foram escolhidas para pesquisa. Além disso, foi adotado como critério que o professor tivesse no mínimo um ano de exercício do magistério e que aceitasse participar da pesquisa, assinando o Termo de Consentimento Livre e Esclarecido (TCLE). Portanto, os professores que não se enquadraram nos critérios de inclusão não participaram da pesquisa, bem como aqueles que não assinaram o TCLE. 
Para a obtenção de informações sobre características comportamentais e emocionais, foi aplicado o SDQ (GOODMAN, 1997; FLEITLICH; CORTÁZAR; GOODMAN, 2000) com os professores, os quais concordaram em participar da pesquisa e assinaram o termo de consentimento livre e esclarecido (TCLE). Os docentes receberam explicações sobre o preenchimento do questionário individualmente por meio de e-mail e responderam a ele.

O Questionário de Capacidades e Dificuldades da Criança - SDQ (GOODMAN, 1997; FLEITLICH-BILYK; GOODMAN, 2001) é um instrumento breve, normalmente utilizado para o rastreamento de problemas de saúde mental em crianças e jovens de quatro a 16 anos, aplicado a pais e professores. É composto por 25 itens divididos em cinco subescalas: problemas no comportamento pró-social, hiperatividade, problemas emocionais, de conduta e de relacionamento, com cinco itens em cada subescala. As respostas podem ser: falso, mais ou menos verdadeiro ou verdadeiro; e cada item recebe uma pontuação específica. A soma de cada escala e a soma total permite a classificação da criança em três categorias: desenvolvimento normal (DN), limítrofe (DL) ou anormal (DA). Na subescala comportamento pró-social, quanto maior a pontuação, menor é a quantidade de queixas. Nas outras subescalas (hiperatividade, problemas emocionais, de conduta e de relacionamento), quanto maior a pontuação, maior o número de queixas.

As crianças e jovens são classificadas em três categorias (normal, limítrofe e anormal) para cada uma das escalas e de acordo com a pontuação total. Os valores de classificação variam de acordo com as escalas. Foi utilizada a versão do instrumento disponível no endereço www.sdqinfo.com (ANEXO A).

Os dados coletados foram organizados e cotados de acordo com as proposições da técnica, após o que foi realizada a digitação dos escores do instrumento em planilhas do editor Microsoft Excel, submetidos então a tratamento estatístico, utilizando o programa SPSS, versão 12.0. O trabalho seguiu os preceitos éticos estabelecidos pela resolução 466/12 tendo como número de aprovação no Comitê de ética em pesquisa 3.900.489.

\section{RESULTADOS E DISCUSSÃO}

Participaram da pesquisa 465 professores que lecionam do $1^{\circ}$ ao $5^{\circ}$ ano, $90 \%$ dos participantes eram do sexo feminino, tinham idade média de 44 anos, máxima de 74 anos e mínima 24 anos, apresentam ensino superior completo, quanto ao quadro dos profissionais da rede de ensino $50,9 \%$ é efetivo e $48,9 \%$ é substituto, 381 desde 
professores trabalham $200 \mathrm{~h}$, representando um total de $82 \%$ nesse universo. Após a análise dados, constatamos que 346 professores possuem especialização, correspondendo a 74,6\% dos participantes. O tempo de experiência como professor é de 1 a 38 anos e o tempo em que atua na escola pesquisada varia de 1 a 12 anos.

Em relação aos aspectos relacionados a fatores emocionais na visão dos professores, os dados evidenciam que muitos destes, atribuem aos estudantes problemas emocionais, que acarretam dificuldades e limitações no processo de aprendizagem. Sendo observados, no gráfico abaixo:

Gráfico 1 - Análise de Frequências dos itens dos sintomas emocionais

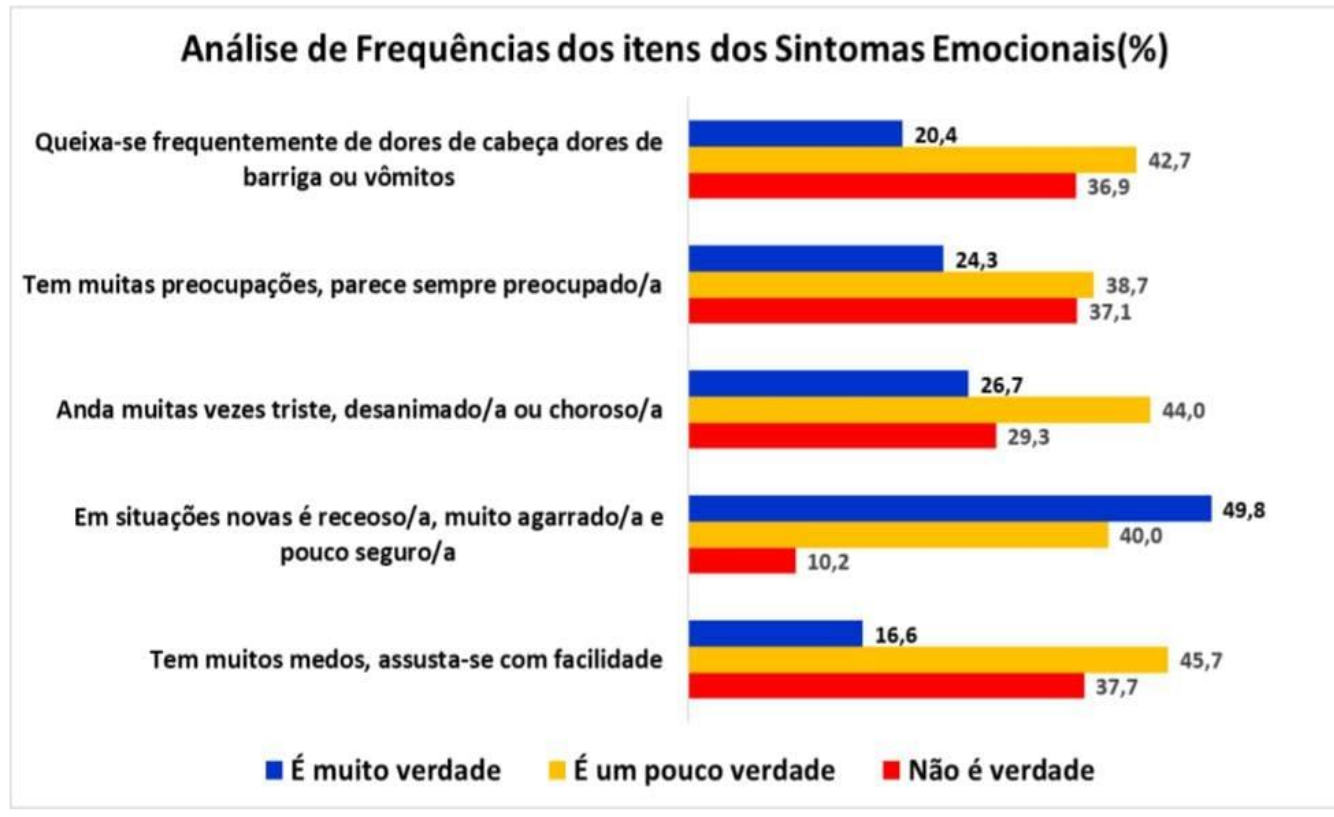

Fonte: Autores (2021).

Os sintomas emocionais demonstram possíveis transtornos de ansiedade, os quais são considerados doenças psiquiátricas que afetam mais crianças e adolescentes, prevalecendo o percentual de $4 \%$ a $20 \%$ desse público, podem ocasionar prejuízos significativos nos processos de atenção e da aprendizagem (CUNHA et al., 2017), por consequência, podem comprometer o desempenho escolar e pessoal dos estudantes.

Os dados são bastante impactantes e revelam que muitos dos estudantes estão acometidos por tais emoções; 62,94\% permanecem sempre preocupados, 44\% estão desanimados e 49,8\% dos estudantes são receosos, demonstrando sofrimento emocional por partes desse público, além do percentual de crianças que demonstram medo, sendo também, bastante significativo $45,7 \%$. 
Na visão dos professores o medo é perceptível nas crianças, sentir medo, faz parte do seu processo de desenvolvimento, e a intensidade varia de criança para criança, pois envolve a sua rede de relações como pais, professores, colegas e a maneira com que eles lidam com essa situação. Com o crescimento e a maturação cognitiva e emocional, a tendência é que a criança supere esse medo (CATARINA et al., 202

De acordo com Queiroz e Guimarães (2014, p. 55), "O medo pode ser definido como sendo um sentimento de insegurança em relação a uma pessoa, a uma situação ou um objeto, é um sentimento pessoal, o que assusta um pode ser indiferente para o outro". Catarina et al. (2020) afirmaram que é necessário que os adultos que participam do seu desenvolvimento, tenham atenção e cuidado ao que a criança está sentindo, pois se ela não receber o apoio e o conforto necessário para a superação do medo, esse quadro pode se tornar patológico.

Em relação ao gráfico, que aborda problemas de comportamento, foi identificado no item referente à raiva e a birras que $40,6 \%$ dos estudantes manifestam momentos com esses. No item relacionado a conflitos com outras crianças, $40 \%$ dos estudantes se envolvem em situações conflituosas com seus pares; e, no item referente à mentira, 40,7\% dos estudantes mentem, de acordo com o que foi informado pelos professores.

Gráfico 2 - Análise de Frequências dos itens dos Problemas de Comportamento

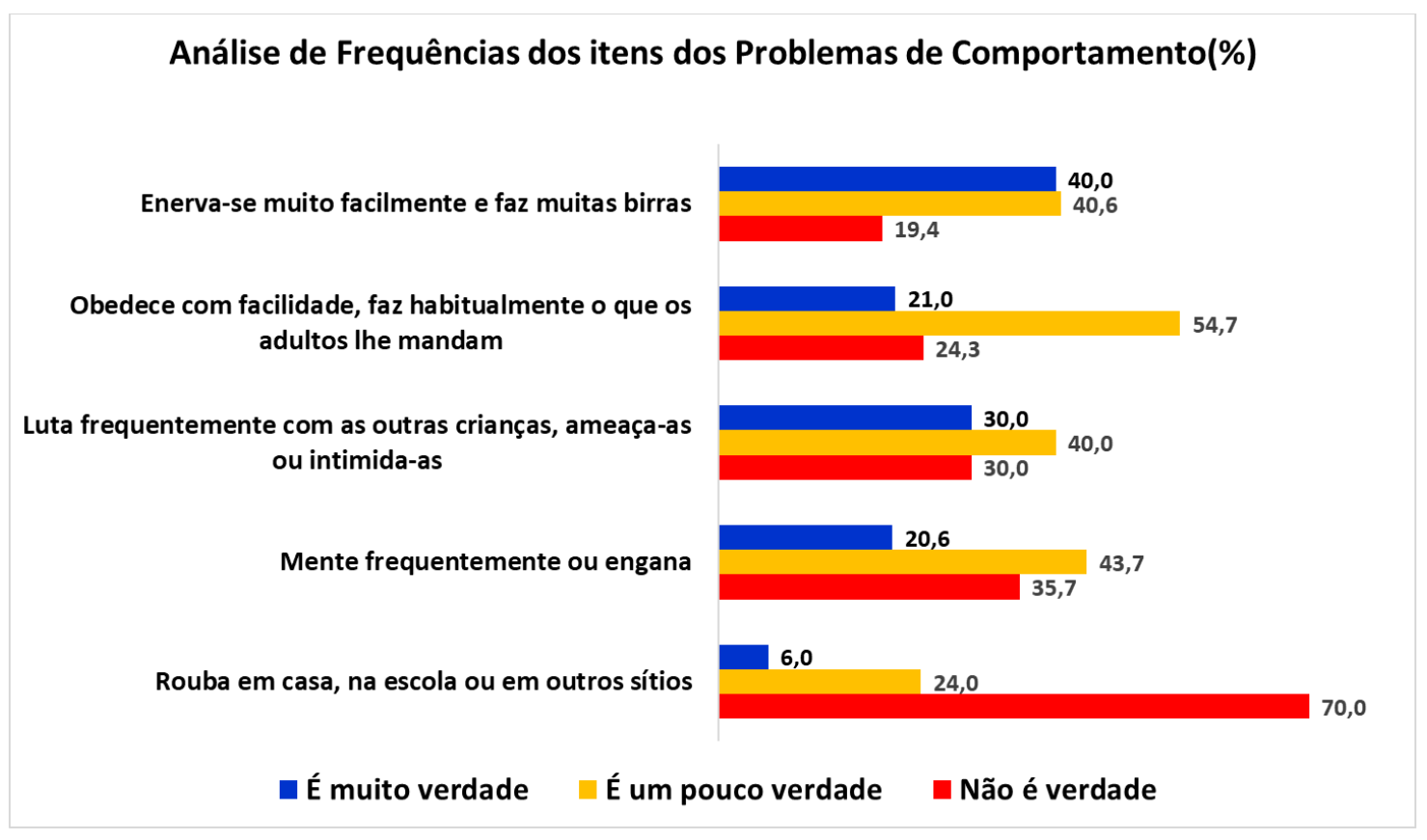

Fonte: Autores (2021). 
Os dados revelam ainda, a eventualidade da violência no ambiente escolar, sendo necessário realizar um estudo mais aprofundado e promover a discussão acerca dessa situação vivenciada, pois quando as crianças demonstram comportamentos como estes, são sinais de situações conflitantes que experienciam, refletindo diretamente nos demais espaços sociais em que estão inseridas.

Uma pesquisa realizada comparou dois grupos de crianças, ambos do sexo masculino, um grupo composto por crianças que apresentavam comportamentos agressivos na escola e o outro grupo de crianças que não apresentam tais comportamentos, concluíram que as crianças que apresentavam agressividade no ambiente escolar têm histórico de maior incidência de exposição à violência doméstica. O termo técnico utilizado para descrever a situação vivenciada pela criança que assisti a violência praticada pelo seu pai ou padrasto contra sua mãe, configura-se à exposição de violência doméstica. Estudos corroboram que a exposição das crianças à violência doméstica, acarreta sérios problemas comportamentais e emocionais (WILLIAMS \& PEREIRA, 2008).

De acordo com Szymanski e Alves (2011), a violência ocasiona sofrimento, danos físicos e psicológicos, humilhação, desespero, desamparo, desesperança e revela a barbárie na qual todos podem se tornar vítimas.

Sendo necessário observar e realizar intervenções quanto aos menores sinais de violência escolar, pois estudos apontam que no ambiente escolar, acontecem vários tipos agressões como a física, a verbal e a psicológica, que acarretam e afetam o desenvolvimento e a aprendizagem dos estudantes. Portanto o ambiente escolar, deve promover aos estudantes momentos de escuta, diálogo e o desenvolvimento de habilidades sociais, as quais para serem executadas precisam estar em consonância com um espaço acolhedor, saudável e seguro.

Em relação ao gráfico que trata de problemas de relacionamentos com os colegas, os elementos apresentados, corroboram para a compreensão que há um alto índice de isolamento por parte dos estudantes.

\section{CONCLUSÃO}

Conclui-se que na percepção dos professores participantes da pesquisa, a maioria dos estudantes apresenta comportamentos que discrepam dos parâmetros preestabelecidos pela instituição escolar, o que ocasiona várias indagações a respeito dos 
dados coletados e que para serem respondidas será necessário a imersão nesse contexto escolar, para compreender de fato, o papel da escola para solucionar esses impasses escolares, se a escola percebe-se como responsável nessa dinâmica da queixa escolar e como transformar esse cenário que tem sido recorrente nos últimos anos, ou melhor, nas últimas décadas.

A busca por entender as causas do crescente número de estudantes com problemas no contexto escolar conduz à necessidade de consideração de fatores diversos, com um olhar ora centrado nos professores, que muitas vezes se sentem impotentes e angustiados em lidar com os estudantes que não conseguem aprender da maneira como o ensino é ofertado nas escolas; ora voltado para as famílias, que saem em busca de um diagnóstico, acreditando que essa seja a solução para os problemas apresentados pelo seu filho no espaço escolar; ora, ainda, focado nos estudantes que sofrem por perceberem o olhar desqualificador dos seus professores que não acreditam na sua capacidade de aprender e acabam transferindo-os a outros profissionais para que estes descubram as causas dos problemas ou limitações desses alunos.

É importante que tanto os profissionais da educação, quanto os profissionais da saúde trabalhem em parceria e mantenham o diálogo contínuo, acerca da percepção que tem da criança e conversem com a família, com intuito de apoiá-la e de compreender melhor como esse estudante se comporta nos demais espaços de sua convivência, buscando minimizar os prejuízos no seu desenvolvimento emocional, cognitivo e social, oferecendo meios para atender com qualidade e equidade as necessidades dos estudantes.

As conclusões deste estudo ratificam as impressões da literatura pertinente sobre o tema, que aponta que, quando os estudantes demonstram dificuldades ou fogem das expectativas esperadas, são, muitas vezes etiquetados com problemas, como se essa situação pertencesse unicamente a eles, sem considerar todos os atores envolvidos no contexto escolar, os quais são imprescindíveis por fazerem parte da vida desses estudantes.

Desse modo, é primordial que a escola oportunize momentos de escuta e de diálogo com os professores, com o intuito de propiciar reflexões sobre as situações vivenciadas no contexto escolar, e buscar promover a construção de um novo olhar diante dos estudantes, considerando suas singularidades e a possibilidade de se adotarem novas práticas que acolham e atendam à multiplicidade dos estudantes, para a promoção do potencial de cada criança e adolescente ao longo de sua formação educacional. 


\section{REFERÊNCIAS}

CATARINA, C. S. et al. Importância de estudar o medo no desenvolvimento infantil. Anuário Pesquisa e Extensão Unoesc, São Miguel do Oeste, v. 5, p. 23922, mar. 2020.

CUNHA, N. B. et al. Ansiedade e desempenho escolar no ensino fundamental I. Educação, Santa Maria, v. 42, p. 397, 2017.

FLEITLICH-BILYK, B.; GOODMAN, R. Social factors associated with child mental health problems in Brazil: cross sectional survey. British Medical Journal, Londres, v. 323, p. 599-600, 2001.

FLEITLICH, B.; CORTÁZAR, P. G.; GOODMAN, R. Questionário de capacidades e dificuldades (SDQ). Infanto - Revista de Neuropsiquiatria da Infância e Adolescência, São Paulo, v. 8, n. 1, p. 44-50, 2000.

GATTI, B. A. A construção metodológica da pesquisa em educação: desafios. Revista Brasileira de Política e Administração da Educação, Porto Alegre, v. 28, n. 1, p. 1334, jan./abr. 2012.

GIL, A.C. Como elaborar projetos de pesquisa. 4. ed. São Paulo: Atlas, 2008.

GOODMAN, R. The strengths and difficulties questionnaire: a research note. Journal of Child Psychology and Psychiatry, Londres, v. 38, p. 581-586, 1997.

MOYSÉS, M. A. A. Fracasso escolar: uma questão médica? São Paulo: FDE 1990.

PATTO, M. H.S. A produção do fracasso escolar: história de submissão e rebeldia. São Paulo: T. A. Queiroz, 1990.

PEREIRA, G.; ORTIGÃO, M. I. Pesquisa quantitativa em educação: algumas considerações. Revista Periferia, Duque de Caxias, v. 8, n. 1, p. 66-79, 2016.

QUEIROZ, Z. F. R.; GUIMARÃES, J. M. C. O medo em crianças de infâncias diferenciadas. Revista Intercâmbio, v. 53, p. 53-75, 2014.

ROSSATO, M. O movimento da subjetividade no processo de superação das dificuldades de aprendizagem escolar. Orientadora: Albertina Mitjáns Martínez. 2009. 240 f. Tese (Doutorado em Educação) - Universidade de Brasília, Brasília 2009.

RUDIO, F. V. Introdução ao projeto de pesquisa científica, 3. ed. Petrópolis: Vozes, 2002.

SOUZA, B. P. Orientação à queixa escolar. São Paulo: Casa de Psicólogo, 2007.

SOUZA, M. P. Psicologia escolar e educacional em busca de novas perspectivas.

Psicologia escolar e educacional, São Paulo, v. 13, n. 1, p. 179-182, 2009. 
SZYMANSKI, M. L. S.; ALVES, M. F. Dando voz aos alunos: uma alternativa para a prevenção da violência e do fenômeno bulling na escola. In: SEMINÁRIO

INTERNACIONAL DE REPRESENTAÇÕES SOCIAIS, SUBJETIVIDADE E

EDUCAÇÃO, 1., 2011, Curitiba. Anais. Curitiba: Champagnat, 2011. v. 1. p. 1-13.

WILLIAMS, L. C. A.; STELKO-PEREIRA, A. C. A associação entre violência doméstica e violência escolar: Uma análise preliminar. Educação. Teoria e Prática, Rio Claro, v. 18, p. 25-35, 2008.

Recebido em: 15/09/2021

Aprovado em: 10/10/2021

Publicado em: 18/10/2021 